\title{
Influencing Factors and Promotion Strategies of Communication Ability of College Students in the West China
}

\author{
Xiyu Liu, Jinbin Hao \\ School of Economics and Management, Inner Mongolia university of Science and Technology,Baotou street \\ 7,China \\ 773625529@qq.com Qenpenbian@163.com
}

Keywords: Undergraduate; Communication Ability; Factor Analysis

\begin{abstract}
With the increasing emphasis on the communication ability in contemporary talent competition, cultivation of the college students' communication ability also attracts the attention of colleges and universities. Taking college students as the research objects, this paper discusses and analyses the present communication ability status of the undergraduates in West China through questionnaires and quantitative statistical analysis. It is found that students generally lack sufficient and flexible communication ability. Hence, some strategies to promote communication ability in them are formulated.
\end{abstract}

\section{Introduction}

National medium and long-term education reform and development plan outline (2010-2020) presented the goal of achieving a higher level of compulsory universal education--to further improve the level of popularization of higher education, to increase the enrolment rate of higher education to $40 \%$ by 2020 and thus double the number of people who have received higher education in 2009. This means that the proportion of people having higher education background will be increased. Therefore, based on the requirement of the overall social competitiveness of ascension, cultivation and promotion of college students' interpersonal communication ability and become important issues. As a developing economic area, the western region of China has a potential demand for high-quality group. In the western region, college students' interpersonal and communication skills have a directly impact on the overall quality of the college students.

\section{Influencing factors of communication ability in college students}

The discretion of the college students' communication ability directly affect college students interpersonal relationship and, in return, has a great influence on their campus life, resulting in positive or negative attitudes towards life. According to an investigation, college students' communication ability is the result of joint action of multiple factors.

\subsection{Factors-college students themselves}

On this stage, when students are at this age, their psychological maturity develops more slowly than physical maturity. On one hand, due to college students' self-consciousness awakening, they drastically ask for their own independent thinking and selecting of varying needs and behaviours to develop their own unique lifestyles. On the other hand, because they are in short of social experience and their psychological feature of being excessively idealistic cannot meet the needs of physical development lead to conflict and ambivalence in mental realm. If this ambivalence cannot be guided and released properly, it may significantly influence the interpersonal relationships between college student individuals.

\subsection{Factors - environment and family}

Most students come from the western region, economically underdeveloped area and as is known that the reality of economic social atmosphere affects college students in their whole process of growth. Underdeveloped economic and social reality often determines that the whole social atmosphere is in a closed state, which, however, conflicts with the undergraduate's demand for 
openness and accommodation. Meanwhile, during the period of social transition, traditional familystyle structure and household education both have been impacted, while the new family structure and advanced domestic education method are just under the way. The household circumstances under which students grew up constantly undergo profound changes affect the social cognition and social communication of students in the western region.

\subsection{Factors - atmosphere of college}

As a place for the undergraduate to live and study, campus is of substantially environmental importance to the communication ability of the college students, especially during the transition period from high school to college in which the lifestyle and learning pattern have changed a lot. Pre-college individual lifestyle is replaced by a collectivization lifestyle, which easily causes discomfort, more commonly among the freshmen. Curricula in college highly value the education of knowledge and theories, but ignore the guidance of psychology and interpersonal relationship. Under this education pattern, college students confronting emotional disorder generally do not know how to release, consequently coming across communication obstacles.

\subsection{Social situation and technology revolution factors}

Social environment has a profound and comprehensive effect on college students who are still in development mentally, physically and psychologically. The rapidly-developing and drastically-transforming society is constantly refreshing the learning attitude of the undergraduates. The progress of technology revolution, especially the development of network technology shifted the main communication mode of the undergraduates from traditional face-to-face to virtual world. Although this mode shortens the distance between people and blocks the practical discrepancy in real life: social status, occupation, background and so on, and provides a new and convenient communication channel. But this way of communication reduces the chance of directly emotional communication, once contemporary college students cannot overcome the realistic communication obstacles they will flee to virtual world looking for recovery, which is a negative attitude toward real life.

\section{MEASUREMENT OF COMMUNICATION ABILITY OF THE UNDERGRADUATES IN WESTERN REGION}

Based on the interpersonal communication system structure presented by Spitzberg and Shuhua Zhang, and referring to the communication theory, communication structure and the corresponding empirical study by other predecessors, this article divided communication abilities into communication skills, communication cognition and communication propensity. Communication skill is the behavior ability, communication cognition is the ability to accurately understand and correctly judge oneself, others and communication atmosphere. Communication propensity is the preference and motivation of communication.

Referring to the interpersonal communication ability inventor in psychological realm, the questionnaire of college students' interpersonal communication ability is revised to test its reliability and validity. Setting students from different departments, different grades and different majors in one university as the research objects, distributing 300 questionnaires, through recycling questionnaires, eliminating invalid questionnaires, counting and disposing the statistics by SPSS, analysing the result and drawing conclusions, this paper analyses the present status and causes of college students' interpersonal communication ability.

\subsection{College students' communication ability ternary structure model and the questionnaire}

This study refers to the general interpersonal skills of ternary structure by Shuhua Zhang, directing at the characteristics of the college students interpersonal communication, setting up college students' interpersonal communication ability structure: communication cognition as directional adjustment, communication skills responding to the interchanging with exterior and the communication propensity as motivation. As shown below:

The questionnaire is compiled according to the theory of college students' interpersonal communication ideas of three dimensions. The first dimension "communication skills" consisting of nine questions, the second dimension "communication cognition" of eight questions, the third 
dimension "communication prosperity" of 10 questions, there are 27 questions in total, all items in random arrangement, using the self-assessment type of Liker's 5-point-scale method, from "fits", "satisfied", "largely in line with", "don't conform to", "completely does not conform to", in order to get 5 points, 4 points, three points, 2 points, 1 point, higher scores signifing higher communication ability.

\subsection{Reliability and validity test of questionnaire}

The inner reliability of the questionnaire aimed at testing college students' interpersonal communication ability is identified by Cronbach's Alpha. Therefore, according to the table 1, the Cronbach's Alpha of this questionnaire is 0.427 , which means a good reliability.

Table 1 Cronbach’s Alpha

\begin{tabular}{|c|c|c|}
\hline Cronbach's Alpha & $\begin{array}{c}\text { Based on the standardization of } \\
\text { Cronbachs Alpha }\end{array}$ & Number of terms \\
\hline .427 & .428 & 3 \\
\hline
\end{tabular}

Assessment of the correlation coefficient matrix of factors shows that the correlation coefficient of all factors is comparatively ideal except communication cognition, which show that the questionnaire in this study has good content validity and structure validity.

Bartlett test of sphericity and Kaiser-Meyer-Olkin test are the premises of factor analysis. Bartlett test of sphericity is used to test whether the correlation matrix is unit matrix, in other words to test if all variables are independent. After a preliminary analysis of the questionnaire, the result is 1886 in Bartlett test of sphericity, and significance level is 0.000 , which means the difference is significant statistically, showing the statistics from the questionnaire is suitable for factor analysis due to the possibility of shared factors between variables. Illustrated in the following table 2:

The result that KMO is 0.728 is got by using the factor analysis of SPSS, and Bartlett test of sphericity results is statistically significant. The original 27 variables can be classified into nine common factors, which can explain $61.832 \%$ of the total variance. These results verify the dimension of the college students' interpersonal communication structure is reasonable. In consequence, the questionnaire is believed to possess good validity and the questionnaire results are highly in accordance with the actual condition of college students' interpersonal communication ability.

Table 2 Correlation between matrix

\begin{tabular}{|c|c|c|c|c|}
\hline & $\begin{array}{c}\text { Communication } \\
\text { propensity }\end{array}$ & $\begin{array}{c}\text { Communication } \\
\text { skills }\end{array}$ & $\begin{array}{c}\text { Communication } \\
\text { cognition }\end{array}$ & $\begin{array}{c}\text { Communication } \\
\text { ability }\end{array}$ \\
\hline $\begin{array}{c}\text { Communication } \\
\text { propensity }\end{array}$ & 1.000 & .373 & .040 & .749 \\
\hline $\begin{array}{c}\text { Communication } \\
\text { skills }\end{array}$ & .373 & 1.000 & .186 & .745 \\
\hline $\begin{array}{c}\text { Communication } \\
\text { cognition }\end{array}$ & .040 & .186 & 1.000 & .546 \\
\hline $\begin{array}{c}\text { Communication } \\
\text { ability }\end{array}$ & .749 & .745 & .546 & 1.000 \\
\hline
\end{tabular}

Table 3 KMO and Bartlett test

\begin{tabular}{|c|c|c|}
\hline \multicolumn{2}{|c|}{ Sampling enough degrees of Kaiser - Meyer - Olkin measurements } & .728 \\
\hline \multirow{3}{*}{$\begin{array}{c}\text { Bartlett test of } \\
\text { sphericity }\end{array}$} & The approximate chi-square & 1886.118 \\
\cline { 2 - 3 } & df & 351 \\
\cline { 2 - 3 } & Sig. & .000 \\
\hline
\end{tabular}




\subsection{Statistical analysis of college students' communication ability}

This study taking a comprehensive university in the western region as example, in which most of the students come from all parts of the country, is certainly of great representativeness. The objects of the study, undergraduate college students, were chosen from Grade 2011, Grade 20012, Grade 2013 and Grade 2014. In this survey, 300 questionnaires were handed out and recycled, the integrity and authenticity of the answers were checked, then invalid questionnaires were eliminated, and finally 289 effective questionnaires were collected, effective rate being $96.3 \%$.

The result of independent sample test of grade differences in college students' interpersonal communication ability:

Table 4 uses the multiple independent sample test to investigate three influencing factors of the undergraduates' communication ability, respectively cognition, skills and propensity of communication. By this research we can find out that the undergraduates have great grade difference both in communication cognition and in communication ability while, in contrast, that difference does not occur in communication skills and propensity.

It can be recognized from the table that most college students' communication ability is in ordinary level and only a few of them are above or below the normal level. It suggests that in general, college students' interpersonal communication ability and the level of the three factors are relatively mediocre. In the research on the current situation of college students' interpersonal communication by Lifen Zhu, the author discovers that undergraduates are in great need of interpersonal communication, but act inversely due to a short of initiative. Thus although college students have the basic ability to communicate, but still lack systematic and deep training of communication, unable to adapt themselves to communication with different people.

Table 4 Scores in factors of respondents in different grades and the results of multiple independent sample tests

\begin{tabular}{|c|c|c|c|c|}
\hline & $\begin{array}{c}\text { Grade 1 } \\
(\mathrm{M} \pm \mathrm{SD})\end{array}$ & $\begin{array}{c}\text { Grade } 2 \\
(\mathrm{M} \pm \mathrm{SD})\end{array}$ & chi-square & $\mathrm{p}$ \\
\hline Communication cognition & $23.21 \pm 2.743$ & $26.61 \pm 3.875$ & 50.060 & .000 \\
\hline Communication skills & $26.75 \pm 4.104$ & $26.98 \pm 4.042$ & 3.580 & .310 \\
\hline Communication propensity & $30.24 \pm 4.395$ & $31.38 \pm 5.451$ & 6.303 & .098 \\
\hline Communication ability & $80.20 \pm 8.185$ & $84.97 \pm 8.756$ & 17.485 & .001 \\
\hline & $\begin{array}{c}\text { Grade 3 } \\
(\mathrm{M} \pm \mathrm{SD})\end{array}$ & $\begin{array}{c}\text { Grade } 4 \\
(\mathrm{M} \pm \mathrm{SD})\end{array}$ & chi-square & $\mathrm{p}$ \\
\hline Communication cognition & $26.84 \pm 3.550$ & $23.60 \pm 6.229$ & 50.060 & .000 \\
\hline Communication skills & $27.79 \pm 3.673$ & $29.20 \pm 5.805$ & 3.580 & .310 \\
\hline Communication propensity & $30.29 \pm 4.575$ & $31.60 \pm 6.348$ & 6.303 & .098 \\
\hline Communication ability & $84.92 \pm 8.244$ & $84.40 \pm 15.566$ & 17.485 & .001 \\
\hline
\end{tabular}

\section{CONCLUSIONS AND developing}

Through investigation and analysis, the current situation of college students interpersonal communication ability was comprehended. Then aiming at the problems in their interpersonal communication ability and the factors influencing interpersonal communication skills, from the exploration perspectives of students, schools, socity and family, to encourage them to further improve the interpersonal communication ability, , there is a need to teach them basic strategies in communication, reform the education pattern of school, complete the communication system of education, strengthen psychological education and develop students' consciousness as main communication entities. 


\subsection{Teaching the basic principles of interpersonal communication}

The principle of honesty is the foundation of communication, without which communication cannot be performed; the principle of equality is the premise of communication, the assurance of a smooth communication; the principle of comprehensiveness is the platform of communication, the carrier of good contacts; the appropriate principle is the initiation of communication, ensuring communication goes well in appropriate range. The principle of mutual benefit is the purpose of communication, a necessary and sufficient condition for good communication.

\subsection{Improving interpersonal skills}

Interpersonal skills are the techniques, methods and art used in the process of establishing and handling interpersonal relationship. It is the embodiment of principle of interpersonal relationship with significant operability. Interpersonal skills are of great significance for the establishment and development of interpersonal relationship, for they are the keys to success of human interpersonal behaviour and they determine the degree of optimizing personal relationship. Interpersonal skills are varied, which can be divided into different types according to the needs of different people and angles. From the perspective of the object of skill effect, it can be divided into three main categories: self operation, object operation and others-myself communication method.

\subsection{Developing basic interpersonal psychology}

Psychological health of college students exerts a significant impact on communicative behaviour and ability. The findings of the survey of college students' mental health show that the psychological quality of college students is not stable, inferiority, jealousy and suspicion etc. are the most common negative aspects, which are the main psychological barriers to the development of college students' interpersonal communication ability. To improve college students' interpersonal skills we must guide students to overcome these negative mentality and to have right attitudes towards communication

\subsection{Optimize the family environment to create a harmonious family}

Environment is an important resource of education, the proper creation and utilization of which can effectively foster the progress of students. As the first school of interpersonal relationships, children's interpersonal skills are first formed in the process of emotional communication with the family. Basic language habits, interactions, expressions, gestures and other methods needed in interpersonal relationship are learned from the emotional communication with parents during the childhood, so family environment directly decides the attitude of children when making interpersonal communication, and then determines the success of personal communication. Children who are more likely to communicate successfully will feel happy, while, oppositely children who are not easily accepted by peers will reduce to psychological inferiority or manic, their emotions fluctuating frequently. Paying attention to the children's emotional experience and feelings is of great priority to the healthy development of children emotion and ability to communicate with others.

4.5 University should set courses related to communication education, delicately design the content and method of curriculum

The university should offer programs such as "effective communication", "the art of communication", "social etiquette" or "speech and eloquence" etc. to expand the theoretical knowledge of communication, which could inspire student to be aware of the significance of communication. Colleges should include students' communication education into the students' quality education, delicately design the content and method of curriculum, completing the selfconstruction from dressing styles, behaviors to language through aesthetic education.

\section{Acknowledgements}

Study on Ideological and political education of college students in the Inner Mongolia (Number: NJSZ1406); The Inner Mongolia social sciences planning project (Number: 2015jdb029), Innovation fund projects funded in Inner Mongolia university of science and technology (number: 2012ncl045); University student science and technology innovation fund project (Number: 2015069). 


\section{References}

[1] Autman, H., Kelly, S., Gaytan, J., \& Hunter, S. 2016. Measuring High School Students' communication readiness: does communication apprehension, writing ability, and speaking ability correlate with students' perceptions of professional appearance. The journal of research in business education, pp, 57(2), 42.

[2] Chen Hua, Gan Xuehua, Xu Tianyao. 2014. Based on the network communication of the investigation of the ideological and political education [J]. Education teaching BBS, pp.,09:137

[3] Dyson, B., \& Strachan, K. 2017. Co-operative learning in a high school physical education programm. Waikato Journal of Education, pp. 6(1),826-843.

[4] Fu Mei, 2005, College students' general self-efficacy and interpersonal relationship [M]. Anhui Normal University, pp,07:12-26

[5] Liu Yong, Peng Xinmei. 2012. The communication model research college teachers and students under the network environment [J]. Education teaching BBS, pp,01: 45

[6] Lipscombe, B., Boyd, R. N., Coleman, A., Fahey, M., Rawicki, B., \& Whittingham, K.,2016. Does early communication mediate the relationship between motor ability and social function in children with cerebral palsy. Research in developmental disabilities, pp. 53, 279-286.

[7] Ma Zongxia, 2004. College students' interpersonal communication ability present situation investigation and study [J]. Journal of Beijing institute of technology (social science edition), pp.,06:57

[8] Zhu Lifen, Dai Zuliang. 2009, The current situation of college students' interpersonal communication research. [J]. China's education and social science. 